\title{
Factors associated with failure to achieve remission and with relapse after remission in patients with major depressive disorder in the PERFORM study
}

This article was published in the following Dove Press journal:

Neuropsychiatric Disease and Treatment

9 August 2017

Number of times this article has been viewed

\author{
Delphine Saragoussi' \\ Maëlys Touya ${ }^{2}$ \\ Josep Maria Haro ${ }^{3}$ \\ Bengt Jönsson ${ }^{4}$ \\ Martin Knapp ${ }^{5}$ \\ Bastien Botrel ${ }^{6}$ \\ loana Florea ${ }^{7}$ \\ Henrik Loft ${ }^{8}$ \\ Benoît Rive ${ }^{9}$
}

'Real-World Evidence and Epidemiology, Lundbeck SAS, Issyles-Moulineaux, France; ${ }^{2} \mathrm{Health}$

Economics and Outcomes Research, Lundbeck, Deerfield, IL, US; ${ }^{3}$ Research and Teaching Unit, Parc Sanitari Sant Joan de Deu, CIBERSAM, University of Barcelona, Sant Boi de Llobregat, Barcelona, Spain; ${ }^{4}$ Department of Economics, Stockholm School of Economics, Stockholm, Sweden; ${ }^{5}$ Department of Health Policy, London School of Economics and Political Science, London, UK; ' ${ }^{6}$ Biostatistics, Inferential, Paris, France; ${ }^{7} \mathrm{Clinical}$ Research Paediatrics, H. Lundbeck A/S, Valby, Denmark; ${ }^{8}$ Biometrics, H. Lundbeck A/S, Valby, Denmark; ' $\mathrm{Global}$ Analytics, Lundbeck SAS, Issy-lesMoulineaux, France
Correspondence: Maëlys Touya Lundbeck LLC, 6 Parkway North, Deerfield, IL 600I5, US

Tel + I 2247277423

Email mtou@lundbeck.com
Background: The Prospective Epidemiological Research on Functioning Outcomes Related to Major Depressive Disorder (PERFORM) study has been initiated to better understand the course of a depressive episode and its impact on patient functioning. This analysis aimed to identify sociodemographic and clinical factors associated with failure to achieve remission at month 2 after initiating or switching antidepressant monotherapy and with subsequent relapse at month 6 for patients in remission at month 2 .

Materials and methods: This was a 2-year observational cohort study in 1,159 outpatients aged 18-65 years with major depressive disorder initiating or undergoing the first switch of antidepressant monotherapy. Factors with $P<0.20$ in univariate logistic regression analyses were combined in a multiple logistic regression model to which backward variable selection was applied (ie, sequential removal of the least significant variable from the model and recomputation of the model until all remaining variables have $P<0.05$ ).

Results: Baseline factors significantly associated with lower odds of remission at month 2 were body-mass index $\geq 30 \mathrm{~kg} / \mathrm{m}^{2}$ (OR 0.51), depressive episode $>8$ weeks (OR 0.51), being in psychotherapy (OR 0.51), sexual dysfunction (OR 0.62), and severity of depression (OR 0.87 ). Factors significantly associated with relapse at month 6 were male sex (OR 2.47), being married or living as a couple (OR 2.73), residual patient-reported cognitive symptoms at 2 months (OR 1.12 per additional unit of Perceived Deficit Questionnaire-5 score) and residual depressive symptoms at 2 months (OR 1.27 per additional unit of Patient Health Questionnaire-9 score). Conclusion: Different factors appear to be associated with failure to achieve remission in patients with major depressive disorder and with subsequent relapse in patients who do achieve remission. Patient-reported cognitive dysfunction is an easily measurable and treatable characteristic that may be associated with an increased likelihood of relapse at 6 months in patients who have achieved remission.

Keywords: major depressive disorder, remission, relapse, patient-reported cognitive dysfunction

\section{Introduction}

Major depressive disorder (MDD) is a chronic and recurring condition that affects more than 120 million people worldwide and ranks among the top ten causes of global disability. ${ }^{1,2}$ Patients with MDD report substantial deficits in daily functioning ${ }^{3}$ that equal or exceed those associated with other severe chronic medical conditions, such as diabetes and congestive heart failure. ${ }^{4}$ Multiple domains of functioning may be impaired $;^{4}$ consequently, MDD can have a significant impact on both quality of life and work productivity., 
In terms of clinical management of MDD, the primary objective is to achieve remission. However, despite therapeutic advances, a considerable proportion of patients fail to achieve this goal. Meta-analyses of results of controlled clinical trials have generally shown remission rates of $30 \%-50 \%$ after $6-8$ weeks of treatment with currently available antidepressants. ${ }^{7-12}$ Remission rates are even lower in routine practice settings. In the US STAR*D study - a large trial designed to assess the efficacy of sequential acute treatments for MDD - only 30\%-40\% of patients achieved remission after adequate treatment with a firstline antidepressant. ${ }^{13,14}$ In addition, approximately a third of patients failed to achieve remission after trials of as many as four different antidepressants. ${ }^{14}$ A 12-week remission rate of $31.4 \%$ was reported in the South Korean Clinical Research Centre for Depression study. ${ }^{15}$ Beyond its clinical consequences, failure to achieve remission in MDD is associated with subsequently higher annual health-care resource utilization and expenditure. ${ }^{16-19}$

For patients who have achieved remission, the objective of clinical management is to prevent relapse. However, prevention of relapse in patients who achieve remission is also a challenge for current treatments. In $\mathrm{STAR}^{*} \mathrm{D}$, the 6-month relapse rate was $34 \%-83 \%$, depending on the phase of treatment. ${ }^{13}$ Patients who relapse within 6 months of remission have been shown to have a far worse course of depression over the next 5 years than those who do not relapse within this period of time, as indicated by a significantly greater proportion of time spent with higher levels of severity of depressive symptoms and fewer asymptomatic weeks. ${ }^{20}$

Awareness of sociodemographic or clinical factors that may be associated with failure to achieve remission in patients with MDD or with an increased risk of subsequent relapse in patients who do achieve remission may help to improve clinical management by enabling identification of patients who may require more intensive follow-up and care. Sociodemographic factors that have previously been reported to be associated with failure to achieve remission of MDD include sex, ${ }^{21,22}$ educational level, ${ }^{21,23}$ employment status, ${ }^{21,23}$ and marital status; ${ }^{24}$ clinical factors include depression severity in the acute phase, ${ }^{25,26}$ concomitant mental or chronic medical disorders, ${ }^{21,22}$ and lower functioning and quality of life at baseline..$^{21,24}$ Factors that have been reported to be associated with relapse in patients with MDD include chronicity (ie, presence of previous depressive episodes) $)^{27,28}$ and presence of residual mood symptoms. ${ }^{29}$ Many studies have been undertaken to identify factors that may be associated with poor treatment outcomes in MDD; however, the majority of these have been in highly selected patient populations, which may limit generalization of the findings to routine clinical practice.

The Prospective Epidemiological Research on Functioning Outcomes Related to Major Depressive Disorder (PERFORM) study is an observational cohort study initiated to better understand the course of a depressive episode and its impact on patient functioning over a 2-year period in outpatients with MDD in real-world settings in five European countries. This paper reports planned analyses undertaken to examine potential sociodemographic or clinical factors associated with failure to achieve remission at month 2 and with subsequent relapse at month 6 for patients in remission at month 2. Factors explored included those previously identified in the literature and others, such as cognitive symptoms, which have been identified more recently as relevant in the course of depression and thus have been less extensively studied to date..$^{30,31}$

\section{Materials and methods Study design}

This was a 2-year multicenter, prospective, noninterventional cohort study in outpatients aged 18-65 years with a current diagnosis of MDD (Diagnostic and Statistical Manual of Mental Disorders [DSM]-IV-TR) enrolled by either a primary care physician or a psychiatrist in France, UK, Spain, Germany, and Sweden. This study is registered with ClinicalTrials.gov (NCT01427439). Enrolled patients were either initiating antidepressant monotherapy or undergoing their first switch of antidepressant for a new episode of major depression, with the choice of antidepressant used based on the clinical judgment of the treating physician. Patients receiving antidepressant combination therapy at the time of the initial consultation and patients with schizophrenia or other psychotic disorders, bipolar disorder, substance dependence, mood disorders due to a general medical condition or substances, dementia, or other neurodegenerative diseases significantly impacting cognitive functioning were excluded from study entry. Pregnant women and women $\leq 6$ months' postpartum were also excluded.

\section{Ethics approval and consent to participate}

Ethical approval was obtained for each study site before study initiation following country regulations regarding observational studies:

- France: French health authority (ANSM, previously called AFSSAPS), advisory committee on information 
processing in material research in the field of health (CCTIRS), French data-protection agency (CNIL), French National Medical Council (CNOM) Ethics Committee (CPP Ile de France II); 102 physicians/sites included

- Germany: Munich Ethics Committee, local ethics committees, including Hamburg, Rheinland-Pfalz, Sachsen, and Westfalen-Lippe ethics committees and others; 47 physicians/sites included

- Spain: Agencia Española del Medicamento y Productos Sanitarios (AEMPS), Comités Eticos de Investigaciones Clinicas (CEIC), Comunidades Autónomas (CCAA) of 14 regions; 46 physicians/sites included

- Sweden: Uméå Ethics Committee; 22 physicians/sites included

- UK: Medical Research and Ethics Committee (MREC), National Institute for Health Research (NIHR), and local submissions; 65 physicians/sites included.

All patients provided written informed consent for participation.

\section{Study assessments and data collection}

Study assessments and data collection occurred during routine visits within the normal course of care at baseline, 2 months ( \pm 3 weeks), and 6 months ( \pm 1 month), after which data were collected approximately every 6 months up to 2 years. Patient characteristics recorded included demographic information, history of MDD, characteristics of the current episode of depression, MDD management and resource use, and the presence of any other mental disorder or functional syndrome.

Clinical severity of depression was assessed at all visits by patients using the nine-item Patient Health Questionnaire (PHQ-9) ${ }^{32}$ and by all participating investigators using the Clinical Global Impressions-severity of illness scale (CGI-S). ${ }^{33}$ The Montgomery-Åsberg Depression Rating Scale (MADRS) ${ }^{34}$ was also administered when patients were recruited by psychiatrists. Patient-reported cognitive function was assessed using the five-item Perceived Deficit Questionnaire (PDQ-5), which assesses subjective cognitive symptoms (impairments in memory, concentration, and executive function) over the past 4 weeks. ${ }^{35,36}$ Total score range is $0-20$, with higher scores reflecting greater impairment.

Psychiatrists also assessed the severity of anxiety symptoms using the Hamilton Anxiety Rating Scale. ${ }^{37}$ Other patient-reported questionnaires administered included the Sheehan Disability Scale, ${ }^{38}$ the Work Productivity and Activity Impairment Questionnaire,${ }^{39}$ the 12 -item Short-Form
Health Survey (SF-12), ${ }^{40}$ the EuroQol questionnaire (EQ-5D three-level version; in UK patients only), ${ }^{41}$ the Arizona Sexual Experiences Scale, ${ }^{42}$ and the four-item MoriskyGreen Medication Adherence Scale. ${ }^{43}$

\section{Outcomes}

The primary definition of remission at the 2-month visit was PHQ-9 total score $\leq 9 .{ }^{32}$ If PHQ-9 score was missing, then MADRS total score was used for patients recruited by psychiatrists; remission was defined as a MADRS score $\leq 10 .{ }^{44,45}$ If MADRS score was missing, then remission was defined as a CGI-S score $\leq 2 .{ }^{46}$ For patients in remission at 2 months, relapse at the 6-month visit was defined as: (i) treatment modification (switch or combination) for lack of efficacy at the 6-month visit; ${ }^{47}$ or (ii) PHQ-9 total score $\geq 10$ at the 6-month visit, ${ }^{32}$ or MADRS total score $\geq 22$ at the 6-month visit if PHQ-9 was missing, ${ }^{48}$ or CGI-S score $\geq 4$ at the 6-month visit if PHQ-9 and MADRS were missing. ${ }^{48}$ Relapse status was classified as ambiguous for patients who met criteria for both remission and relapse at month 6 or who were neither remitters nor relapsers at month 6 (eg, MADRS score of 11-21 if PHQ-9 was missing or CGI-S score of 3 if PHQ-9 and MADRS were missing).

\section{Statistical analysis}

The population for analysis comprised all patients who met study inclusion criteria and for whom at least one postbaseline assessment was recorded. Clinically relevant variables recorded at baseline were tested in univariate logistic regression analyses for association with failure to achieve remission at month 2. Clinically relevant variables recorded at baseline and/or at or up to month 2 were tested in univariate logistic regression analyses for association with subsequent relapse at month 6 in patients who achieved remission at month 2 . The variables included in these univariate analyses were selected based on literature review and clinical evaluation (Table 1). Variables with $P<0.20$ in the univariate analyses were then combined in a multiple logistic regression model to which backward variable selection was applied (ie, sequential removal of the least significant variable from the model and recomputation of the model until all remaining variables had $P<0.05$ ). Four factors were forced into the model as adjustment variables because they were identified as potential confounders: country, age, sex, and PHQ-9 total score (at baseline for the remission analysis and at month 2 for the relapse analysis).

Results are presented as ORs with 95\% CIs. By default, ORs for assessment scales and for continuous outcomes are 
Table I Variables selected for univariate analyses to identify factors associated with remission at month 2 and relapse at month 6 for patients in remission at month 2

\begin{tabular}{|c|c|c|}
\hline & Remission & Relapse \\
\hline \multirow[t]{10}{*}{ Sociodemographic factors } & Country & Country ${ }^{51}$ \\
\hline & $\mathrm{Age}^{49}$ & $\mathrm{Age}^{52}$ \\
\hline & $\operatorname{Sex}^{21,22}$ & $\operatorname{Sex}^{27}$ \\
\hline & Tobacco use ${ }^{21}$ & Tobacco use $\mathrm{e}^{53}$ \\
\hline & Educational level ${ }^{21,23}$ & Educational level ${ }^{54}$ \\
\hline & Body-mass index ${ }^{50}$ & Body-mass index $(\mathrm{M} 2)^{27,55}$ \\
\hline & Marital status ${ }^{24}$ & Marital status $(\mathrm{M} 2)^{54}$ \\
\hline & Employment status ${ }^{21,23}$ & Employment status (M2) \\
\hline & Living area & At least one important life event (M2) \\
\hline & At least one important life event & \\
\hline \multirow[t]{3}{*}{ Patient history } & Depressive episode before the visit $^{56}$ & Previous depressive episode $\mathrm{e}^{27,28}$ \\
\hline & Previous depressive episode ${ }^{56}$ & \\
\hline & Time since beginning of this depressive episode ${ }^{25}$ & \\
\hline \multirow[t]{4}{*}{ Comorbidities } & At least one other concomitant mental disorder ${ }^{21,57}$ & At least one concomitant mental disorder $53,59,60$ \\
\hline & At least one chronic medical condition ${ }^{21,22}$ & At least one chronic medical condition \\
\hline & Chronic pain or fibromyalgia ${ }^{22}$ & Chronic pain or fibromyalgia ${ }^{51}$ \\
\hline & At least one anxiety symptom/disorder $21,25,56,58$ & At least one anxiety symptom/disorder $(\mathrm{M} 2)^{25,61,62}$ \\
\hline \multirow[t]{8}{*}{ Resource use and treatment patterns } & Physician specialty & Physician specialty \\
\hline & Current psychotherapy & Previous or current psychotherapy \\
\hline & Sick leave within past 12 months & Treatment stopped between baseline and $M 2$ \\
\hline & Hospitalization for depression over past 12 weeks ${ }^{63}$ & Sick leave (pre-M2) \\
\hline & Switch of antidepressant & Hospitalization for depression (pre-M2) \\
\hline & & Switch of antidepressant (pre-M2) \\
\hline & & MMAS-4 score $(M 2)^{64}$ \\
\hline & & Treatment line (M2) \\
\hline \multirow[t]{8}{*}{ Disease characteristics } & Prior suicide attempt ${ }^{23,63}$ & Suicide attempt (pre-M2) ${ }^{60}$ \\
\hline & PHQ-9 total score ${ }^{25,26,56}$ & PHQ-9 total score $(\mathrm{M} 2)^{51,66}$ \\
\hline & CGI-S score ${ }^{25,26}$ & CGI-S score $(M 2)^{51,66}$ \\
\hline & PDQ-5 total score & PDQ-5 total score (M2) \\
\hline & WPAI-SHP score ${ }^{21,65}$ & WPAI-SHP score $(M 2)^{67}$ \\
\hline & SF-12 - PCS score ${ }^{21,24}$ & SF-I 2 - PCS score $(M 2)^{67}$ \\
\hline & SF-I 2 - MCS score si,24 $^{21}$ & SF-12 - MCS score $(M 2)^{67}$ \\
\hline & Sexual dysfunction ${ }^{a}$ & Sexual dysfunction ${ }^{a}(M 2)$ \\
\hline
\end{tabular}

Notes: aPatients were categorized as having sexual dysfunction if their total ASEX score was $\geq 19$ or their score was $\geq 5$ for one item or $\geq 4$ for at least three items. Variables were selected based on literature review and clinical evaluation. All variables were assessed at baseline, unless otherwise indicated.

Abbreviations: ASEX, Arizona Sexual Experience Scale; CGI-S, Clinical Global Impressions-severity of illness; M2, month 2; MCS, mental component summary; MMAS-4, 4-item Morisky-Green Medication Adherence Scale; PCS, physical component summary; PDQ-5, 5-item Perceived Deficit Questionnaire; PHQ-9, 9-item Patient Health Questionnaire; Pre-M2, prior and up to M2 (any time before baseline, at baseline, or between baseline and M2); SF-12, I2-item Short-Form Health Survey; WPAI-SHP, Work Productivity and Activity Impairment-specific health problem.

given per additional unit. To account for the differences in metrics between scales, ORs for assessment scales were also estimated per additional $0.5 \mathrm{SD}$ to provide a standardized measure and enable comparisons between scales. Supportive analyses were performed by using a forward-selection process instead of backward selection. In addition, for the analysis of factors associated with relapse, alternative definitions for remission and relapse were used to investigate the effect of the PHQ-9 thresholds applied in the study. Alternative definitions included reducing the cutoff used to define remission, placing MADRS before PHQ-9 in the composite definition of remission, increasing the cutoff used to define relapse, and imposing a defined minimum change in PHQ-9 score. These later analyses were conducted using the final model identifying factors associated with relapse at month 6 for patients in remission at month 2 obtained by backward selection. All statistical analyses were performed using SAS version 9.2 (SAS Institute, Cary, NC, US).

\section{Results}

\section{Patients}

A total of 1,895 patients were screened, of whom 1,402 were enrolled in the study. The first patient was screened on February 25, 2011, and the last patient completed the study on February 19, 2015. In all, 1,159 (82.7\%) patients were included in the population for analysis. Reasons for exclusion from the analysis population were violation of at least one of the inclusion and/or exclusion criteria at baseline $(\mathrm{n}=167)$ or lack of 
postbaseline data ( $\mathrm{n}=101$, including 76 who met the inclusion criteria at baseline). The majority of patients were enrolled and followed up by primary care physicians ( $n=969 ; 83.6 \%$ ). At the start of the study, $78.7 \%$ of patients were initiating antidepressant treatment and $21.3 \%$ were switching antidepressant; the treatment status of two patients was unknown.

Remission status was available for 1,112 of the 1,120 patients who attended a month 2 visit (99.3\%). Of these 1,112 patients, 330 were in remission $(29.7 \%)$. Of the 330 patients in remission at month 2, 300 had known relapse status at month $6(90.9 \%)$. Of those, $59(19.7 \%)$ had relapsed at month 6, $226(75.3 \%)$ were in sustained remission, and remission status was ambiguous for 15 (5.0\%). Tables 2 and 3 present baseline data for the different study subpopulations.

\section{Factors associated with failure to achieve remission at month 2}

Statistically significant results $(P<0.05)$ were observed for 18 of the 30 factors of interest included in the univariate analyses (Table 1): switch of antidepressant, body-mass index
(BMI), tobacco use, educational level, time since beginning of this depressive episode, at least one other concomitant mental disorder, chronic pain or fibromyalgia, hospitalization for depression during the 12 weeks before baseline, suicide attempt before baseline, sick leave during the 12 months before baseline, current psychotherapy, PHQ-9 total score, PDQ-5 total score, CGI-S score, percentage activity impairment due to problem, SF-12 physical component summary (PCS), SF-12 mental component summary (MCS), and sexual dysfunction. Living area and at least one chronic medical condition were not statistically significant in univariate analyses; however, since the $P$-values for these factors were below 0.20 , they were also included in the multivariate analysis.

In addition to the four forced adjustment factors (country, age, sex, and PHQ-9 total score at baseline), the final multivariate analysis model retained four factors with $P<0.05$ from the backward-selection process: BMI, time since beginning of this depressive episode, current psychotherapy, and sexual dysfunction (Table 4). Among the forced factors, country and PHQ-9 total score were statistically significant.

Table 2 Baseline sociodemographic characteristics for subsets of patients by remission status at month 2 and by relapse status at month 6 in those who achieved remission at month 2

\begin{tabular}{|c|c|c|c|c|c|c|}
\hline \multirow[t]{2}{*}{ Characteristic } & \multicolumn{3}{|c|}{$\begin{array}{l}\text { Remission status at } \\
\text { month } 2\end{array}$} & \multicolumn{3}{|c|}{$\begin{array}{l}\text { Relapse status at month } 6 \text { in those who } \\
\text { achieved remission at month } 2\end{array}$} \\
\hline & $\begin{array}{l}\text { In remission } \\
(n=330)\end{array}$ & $\begin{array}{l}\text { Not in remission } \\
(n=782)\end{array}$ & $\begin{array}{l}\text { Total } \\
(n=1, I \mid 2)\end{array}$ & $\begin{array}{l}\text { Relapsed } \\
(n=59)\end{array}$ & $\begin{array}{l}\text { Not relapsed } \\
(n=24 I)\end{array}$ & $\begin{array}{l}\text { Total } \\
(n=300)\end{array}$ \\
\hline Age, mean \pm SD (years) & $45.3 \pm 11.9$ & $44.1 \pm 11.9$ & $44.4 \pm 11.9$ & $43.9 \pm 12.1$ & $45.7 \pm 11.7$ & $45.3 \pm 11.8$ \\
\hline Female (\%) & 72.7 & 73.2 & 73.1 & 67.8 & 74.3 & 73.0 \\
\hline \multicolumn{7}{|l|}{ Marital status (\%) } \\
\hline Single & 20.0 & 22.3 & 21.6 & 15.3 & 19.5 & 18.7 \\
\hline Married/couple & 60.0 & 57.9 & 58.5 & 74.6 & 58.5 & 61.7 \\
\hline Divorced/separated & 17.0 & 16.8 & 16.8 & 8.5 & 18.7 & 16.7 \\
\hline Widowed & 3.0 & 3.1 & 3.1 & 1.7 & 3.3 & 3.0 \\
\hline \multicolumn{7}{|l|}{ Education (\%) } \\
\hline No degree or diploma & 2.7 & 4.9 & 4.2 & 1.7 & 2.9 & 2.7 \\
\hline Elementary school & 21.2 & 26.6 & 25.0 & 32.2 & 19.5 & 22.0 \\
\hline High school & 36.4 & 37.4 & 37.1 & 25.4 & 37.3 & 35.0 \\
\hline Non-university degree & 14.2 & 12.9 & 13.3 & 13.6 & 14.9 & 14.7 \\
\hline University degree & 25.5 & 18.2 & 20.3 & 27.1 & 25.3 & 25.7 \\
\hline \multicolumn{7}{|l|}{ Living area (\%) } \\
\hline Rural & 36.1 & 30.1 & 31.9 & 39.0 & 36.5 & 37.0 \\
\hline Urban & 63.9 & 69.9 & 68.1 & 61.0 & 63.5 & 63.0 \\
\hline \multicolumn{7}{|l|}{ Work status (\%) } \\
\hline Paid employment or self employed & 67.9 & 66.4 & 66.8 & 67.8 & 68.9 & 68.7 \\
\hline Tobacco use (\%) & 29.4 & 35.7 & 33.8 & 30.5 & 28.6 & 29.0 \\
\hline \multicolumn{7}{|l|}{ BMI classification (\%) } \\
\hline Normal weight & 50.9 & 45.1 & 46.8 & 42.4 & 52.3 & 50.3 \\
\hline Overweight & 30.3 & 28.7 & 29.2 & 37.3 & 29.5 & 31.0 \\
\hline Obese & 18.8 & 26.2 & 24.0 & 20.3 & 18.3 & 18.7 \\
\hline
\end{tabular}

Note: anformation was missing for one patient for each of age, sex, tobacco use, marital status, living area, and educational level, and for four patients regarding BMI. Abbreviation: BMI, body-mass index. 
Table 3 Medical profile, functioning, and quality of life at baseline for subsets of patients by remission status at month 2 and by relapse status at month 6 in those who achieved remission at month 2

\begin{tabular}{|c|c|c|c|c|c|c|}
\hline \multirow[t]{2}{*}{$\begin{array}{l}\text { Characteristics of current } \\
\text { depressive episode }\end{array}$} & \multicolumn{3}{|c|}{$\begin{array}{l}\text { Remission status at } \\
\text { month } 2\end{array}$} & \multicolumn{3}{|c|}{$\begin{array}{l}\text { Relapse status at month } 6 \text { in } \\
\text { those who achieved remission } \\
\text { at month } 2\end{array}$} \\
\hline & $\begin{array}{l}\text { In remission } \\
(n=330)\end{array}$ & $\begin{array}{l}\text { Not in remission } \\
(n=782)\end{array}$ & $\begin{array}{l}\text { Total } \\
(\mathrm{n}=1,1|| 2)\end{array}$ & $\begin{array}{l}\text { Relapsed } \\
(\mathrm{n}=59)\end{array}$ & $\begin{array}{l}\text { Not relapsed } \\
(n=24 I)\end{array}$ & $\begin{array}{l}\text { Total } \\
(n=300)\end{array}$ \\
\hline Treated with antidepressant before baseline visit (\%) & 16.7 & 23.8 & 21.7 & 20.3 & 15.8 & 16.7 \\
\hline \multicolumn{7}{|l|}{ Time since beginning of this depressive episode (\%) } \\
\hline$<$ I week & 3.3 & 0.8 & 1.5 & 3.4 & 3.3 & 3.3 \\
\hline $\mathrm{I}-2$ weeks & 7.6 & 5.1 & 5.9 & 8.5 & 7.5 & 7.7 \\
\hline $2-4$ weeks & 25.5 & 19.3 & 21.2 & 27.1 & 27.5 & 27.4 \\
\hline 4-8 weeks & 18.5 & 20.9 & 20.2 & 20.3 & 18.3 & 18.7 \\
\hline$>8$ weeks & 45 & 53.9 & 51.3 & 40.7 & 43.3 & 42.8 \\
\hline Significant symptoms of anxiety $(\%)^{\mathrm{a}}$ & 61.2 & 63.2 & 62.6 & 61.0 & 62.7 & 62.3 \\
\hline Symptoms treated with anxiolytics (\%) & 42.6 & 41.6 & 41.9 & 38.5 & 44.3 & 43.2 \\
\hline Currently receiving psychotherapy (\%) & 10.3 & 15.9 & 14.2 & 8.5 & 10.0 & 9.7 \\
\hline \multicolumn{7}{|l|}{ Questionnaire scores, mean \pm SD } \\
\hline PDQ-5 & $9.6 \pm 4.5$ & $12.1 \pm 4.4$ & II. $3 \pm 4.6$ & $11.6 \pm 4.2$ & $8.9 \pm 4.4$ & $9.4 \pm 4.5$ \\
\hline PHQ-9 & $|5| \pm 5.6$. & $18.7 \pm 4.8$ & $17.6 \pm 5.3$ & $16.6 \pm 4.1$ & $14.7 \pm 5.8$ & $15.0 \pm 5.6$ \\
\hline CGI-S & $3.9 \pm 1.1$ & $4.3 \pm 0.9$ & $4.2 \pm 1.0$ & $4.1 \pm 1.0$ & $3.9 \pm 1.2$ & $3.9 \pm 1.2$ \\
\hline MADRS & $31.8 \pm 7.4$ & $33.0 \pm 7.1$ & $32.7 \pm 7.2$ & $33.3 \pm 6.2$ & $31.6 \pm 7.7$ & $32.0 \pm 7.4$ \\
\hline \multicolumn{7}{|l|}{ ASEX } \\
\hline Total score & $20.3 \pm 5.5$ & $21.9 \pm 5.8$ & $21.4 \pm 5.7$ & $20.8 \pm 5.3$ & $20.2 \pm 5.5$ & $20.3 \pm 5.5$ \\
\hline Sexual dysfunction ${ }^{\mathrm{b}}(\%)$ & 75.4 & 84.4 & 81.8 & 70.8 & 76.5 & 75.3 \\
\hline \multicolumn{7}{|l|}{$\begin{array}{l}\text { Other current illnesses } \\
\text { Mental health disorders other than depression (\%) }\end{array}$} \\
\hline Alcohol abuse or dependence & 2.7 & 2.3 & 2.4 & 1.7 & 2.9 & 2.7 \\
\hline Other abuse disorders & 0.3 & 1.5 & 1.2 & 0.0 & 0.4 & 0.3 \\
\hline Somatoform disorders & 6.4 & 8.7 & 8.0 & 6.8 & 6.2 & 6.3 \\
\hline Eating disorders (anorexia, bulimia) & 4.8 & 8.7 & 7.6 & 1.7 & 4.6 & 4.0 \\
\hline Other & 1.2 & 0.3 & 0.5 & 1.7 & 0.8 & 1.0 \\
\hline \multicolumn{7}{|l|}{ Functional syndromes (\%) } \\
\hline Chronic pain & 14.2 & 17.5 & 16.5 & 18.6 & 13.3 & 14.3 \\
\hline Chronic fatigue & 11.8 & 17.9 & 16.1 & 15.3 & 11.6 & 12.3 \\
\hline Fibromyalgia & 3.9 & 8.3 & 7.0 & 5.1 & 3.7 & 4.0 \\
\hline Premenstrual syndrome & 2.7 & 3.7 & 3.4 & 5.1 & 2.1 & 2.7 \\
\hline Sleep disorders & 22.7 & 30.1 & 27.9 & 22.0 & 24.1 & 23.7 \\
\hline Other & 2.4 & 2.9 & 2.8 & 3.4 & 2.5 & 2.7 \\
\hline \multicolumn{7}{|l|}{ Chronic medical conditions (\%) } \\
\hline Cardiovascular disease & 10.9 & 11.3 & 11.2 & 13.6 & 10.8 & 11.3 \\
\hline Diabetes & 4.8 & 4.7 & 4.8 & 0.0 & 5.0 & 4.0 \\
\hline Cancer & 2.1 & 0.8 & 1.2 & 5.1 & 1.7 & 2.3 \\
\hline Rheumatoid arthritis & 0.9 & 1.8 & 1.5 & 0.0 & 0.8 & 0.7 \\
\hline Neurologic disorders & 2.4 & 2.9 & 2.8 & 0.0 & 3.3 & 2.7 \\
\hline Other & 9.7 & 13.8 & 12.6 & 11.9 & 9.1 & 9.7 \\
\hline \multicolumn{7}{|l|}{ Previous depressive episodes } \\
\hline \multicolumn{7}{|l|}{ History of depression (\%) } \\
\hline Previous episode & 57.1 & 56.0 & 56.3 & 61.0 & 55.8 & 56.9 \\
\hline Episode within previous 12 months of previous episode & 23.4 & 25.9 & 25.1 & 27.8 & 24.6 & 25.3 \\
\hline Previous suicide attempt & 8.0 & 16.0 & 13.6 & 16.7 & 5.2 & 7.6 \\
\hline
\end{tabular}

Notes: $\mathrm{n}$ refers to the total number of patients in each subgroup; as not all patients provided data for all parameters, $\mathrm{n}$ is not the denominator for all percentage calculations, and the actual denominator varies between parameters. "Percentages refer to patients "probably" or "definitely" presenting clinically significant symptoms of anxiety according to physician; 'patients were categorized as having sexual dysfunction if their total ASEX score was $\geq 19$ or their score was $\geq 5$ for one item or $\geq 4$ for at least three items. Abbreviations: ASEX, Arizona Sexual Experience Scale; CGI-S, Clinical Global Impressions-severity of illness; PDQ-5, 5-item Perceived Deficit Questionnaire; PHQ-9, 9-item Patient Health Questionnaire; MADRS, Montgomery-Åsberg Depression Rating Scale.

The odds of achieving remission at month 2 were significantly lower for obese patients (BMI $\geq 30 \mathrm{~kg} / \mathrm{m}^{2}$ ), patients with a longer time since the beginning of the depressive episode ( $>8$ weeks vs $<4$ weeks), patients who were in psychotherapy at the beginning of the study, and patients who had sexual dysfunction. The odds of achieving remission at month 2 were $13 \%$ less likely when the PHQ-9 total score increased by 1 unit $(P<0.001)$ and 30\% less likely when PHQ-9 total score 
Table 4 Multivariate logistic regression model for analysis of risk factors of failure to achieve remission at month 2 (backward selection)

\begin{tabular}{|c|c|c|c|c|}
\hline Variable & Category & $n / N(\%)$ & OR $(95 \% \mathrm{Cl})$ & $\overline{P \text {-value }}$ \\
\hline \multirow[t]{5}{*}{ Country } & France & $53 / 158(33.5)$ & 1 & \\
\hline & Spain & $32 / 91(35.2)$ & $1.04(0.57-1.88)$ & 0.900 \\
\hline & UK & $67 / 204(32.8)$ & $1.57(0.93-2.62)$ & 0.089 \\
\hline & Sweden & I I/34 (32.4) & $1.62(0.67-3.91)$ & 0.284 \\
\hline & Germany & $24 / 101$ (23.8) & $0.45(0.24-0.85)$ & 0.013 \\
\hline Age & Per additional year & - & $1.01(0.99-1.02)$ & 0.412 \\
\hline \multirow[t]{2}{*}{ Sex } & Female & $136 / 430(31.6)$ & $\mathrm{I}$ & \\
\hline & Male & $51 / 158(32.3)$ & $0.74(0.48-1.16)$ & 0.187 \\
\hline \multirow[t]{2}{*}{ Body-mass index } & $<30 \mathrm{~kg} / \mathrm{m}^{2}$ & I56/448 (34.8) & $\mathrm{I}$ & \\
\hline & $\geq 30 \mathrm{~kg} / \mathrm{m}^{2}$ & $31 / 140(22.1)$ & $0.5 \mathrm{I}(0.3 \mathrm{I}-0.84)$ & 0.008 \\
\hline Time since beginning of & $<4$ weeks & $70 / 165(42.4)$ & 1 & \\
\hline \multirow[t]{2}{*}{ this depressive episode ${ }^{\mathrm{b}}$} & 4-8 weeks & $34 / 111(30.6)$ & $0.60(0.34-1.05)$ & 0.073 \\
\hline & $>8$ weeks & $83 / 312(26.6)$ & $0.5 \mathrm{I}(0.33-0.8 \mathrm{I})$ & 0.004 \\
\hline \multirow[t]{2}{*}{ Current psychotherapy } & No & $169 / 494(34.2)$ & 1 & \\
\hline & Yes & $18 / 94(19.1)$ & $0.51(0.28-0.93)$ & 0.028 \\
\hline PHQ-9 total score & Per additional unit & - & $0.87(0.84-0.91)$ & $<0.00 \mathrm{I}$ \\
\hline \multirow[t]{2}{*}{ Sexual dysfunction (ASEX) } & No & $49 / 112(43.8)$ & 1 & \\
\hline & Yes & $138 / 476(29.0)$ & $0.62(0.38-0.99)$ & 0.045 \\
\hline
\end{tabular}

Notes: $\mathrm{n}$ refers to the number of patients with remission in each category; $\mathrm{N}$ refers to the total number of patients in each category. ${ }^{\mathrm{a}} \mathrm{Global} P=0.005 ;{ }^{\mathrm{b}} \mathrm{global} P=0.016$. Abbreviations: ASEX, Arizona Sexual Experience Scale; PHQ-9, 9-item Patient Health Questionnaire.

increased by $0.5 \mathrm{SD}$ (2.6 units). As ORs cannot be interpreted as relative risks, these figures are provided only to gain a better understanding of the size of the effect.

The results of the supportive analysis using the forwardselection process were consistent with those obtained using the backward-selection process (base-case analysis). In particular, the same factors were retained by both selection processes. The only factor among those initially selected that had a $P$-value between 0.05 and 0.10 when removed from the multivariate models during the backward-selection process was suicide attempt before baseline $(P=0.0624)$ (Table $\mathrm{S} 1)$.

\section{Factors associated with relapse at month 6}

Statistically significant results $(P<0.05)$ were observed for six of the 30 variables of interest selected to perform the univariate analyses (Table 1): marital status, PHQ-9 total score, PDQ-5 total score, percentage activity impairment due to problem, SF-12 MCS, and suicide attempt (before baseline or between baseline and month 2). CGI-S, SF-12 PCS, and switch of antidepressant (at baseline, between baseline and month 2, or at month 2) were not statistically significant in univariate analyses, but were included in the multivariate analysis $(P<0.20)$.

In addition to the four forced adjustment factors (country, age, sex, and PHQ-9 total score at month 2), the final multivariate analysis model retained two factors with $P<0.05$ from the backward-selection process: marital status and PDQ-5 total score at month 2 (Table 5). Among the forced factors, sex and PHQ-9 total score were statistically significant.

Table 5 Multivariate logistic regression model for analysis of risk factors of relapse at month 6 for patients in remission at month 2 (backward selection)

\begin{tabular}{|c|c|c|c|c|}
\hline Variable & Category & n/N (\%) & OR $(95 \% \mathrm{Cl})$ & $P$-value \\
\hline \multirow[t]{5}{*}{ Country } & France & $11 / 59(18.6)$ & I & \\
\hline & Spain & $5 / 27(18.5)$ & $0.79(0.22-2.82)$ & 0.719 \\
\hline & UK & $15 / 65(23.1)$ & $0.97(0.36-2.64)$ & 0.952 \\
\hline & Sweden & $3 / 9(33.3)$ & $2.15(0.40-11.49)$ & 0.371 \\
\hline & Germany & $3 / 26(11.5)$ & $0.5 \mathrm{I}(0.12-2.22)$ & 0.367 \\
\hline Age & Per additional year & - & $0.99(0.96-1.03)$ & 0.765 \\
\hline \multirow[t]{2}{*}{ Sex } & Female & $21 / 131(16.0)$ & 1 & \\
\hline & Male & 16/55 (29.1) & $2.47(1.05-5.8)$ & 0.037 \\
\hline \multirow[t]{2}{*}{ Marital status (M2) } & Single or divorced/separated or widowed & $8 / 66(12.1)$ & 1 & \\
\hline & Married or living as a couple & $29 / 120(24.2)$ & $2.73(1.05-7.12)$ & 0.040 \\
\hline PHQ-9 total score (M2) & Per additional unit & - & $1.27(1.02-1.59)$ & 0.030 \\
\hline PDQ-5 total score (M2) & Per additional unit & - & $1.12(1.00-1.25)$ & 0.042 \\
\hline
\end{tabular}

Notes: $\mathrm{n}$ refers to the number of patients with relapse in each category; $\mathrm{N}$ refers to the total number of patients in remission at month 2 in each category. ${ }^{\mathrm{a}} \mathrm{Global} P=0.703$. Abbreviations: M2, month 2; PDQ-5, 5-item Perceived Deficit Questionnaire; PHQ-9, 9-item Patient Health Questionnaire. 
The odds of experiencing relapse at month 6 were significantly higher for male patients and patients who were married or living as a couple. Each additional unit of PDQ-5 total score (range $0-20$ ) at 2 months was associated with a $12 \%$ increase in the odds of relapse at 6 months $(P=0.042)$. Each additional unit of PHQ-9 total score (range 0-27) at 2 months was associated with a $27 \%$ increase in the odds of relapse at 6 months $(P=0.030)$. The standardization process to account for the difference in metrics between the two scales showed an additional 0.5 SD in PDQ-5 total score (2.16 units) and PHQ-9 total score (1.18 units) at 2 months to be associated with a similar increase in the odds of relapse at 6 months.

The results of the supportive analysis using a forwardselection process were identical to those obtained using the backward-selection process (base-case analysis). The same factors were retained by both selection processes. The ORs for association with PDQ-5 and PHQ-9 scores were consistent across all alternative definitions of remission and relapse tested, ranging from 1.07-1.14 and 1.08-1.33, respectively (Figures $\mathrm{S} 1$ and $\mathrm{S} 2$ ). The only two factors among those initially selected that had $P$-values between 0.05 and 0.10 when they were removed from the multivariate models during the backward-selection process were suicide attempt before baseline or up to month $2(P=0.0844)$ and SF-12 PCS score at month $2(P=0.0667)$ (Table S2).

\section{Discussion}

Results of this study suggest that different sociodemographic and clinical factors may be associated with failure to achieve remission compared with relapse in patients with MDD. Baseline sociodemographic and clinical factors that appeared to be associated with a reduced likelihood of achieving remission at month 2 were severity of depression (assessed by PHQ-9 total score), obesity, longer duration of depression, being in psychotherapy, and sexual dysfunction. The finding that baseline severity of depression and longer duration of depression were associated with the likelihood of remission was expected. ${ }^{15,21,68}$ Other studies have also suggested that overweight or obese patients may be less likely to achieve remission of MDD. ${ }^{50}$

The finding that baseline sexual dysfunction increased the likelihood of failing to achieve remission was more unexpected. Although sexual dysfunction is known to be linked to serotonergic neurotransmission and to be associated with depression and antidepressant treatment, sexual dysfunction may also be a trigger for depression. ${ }^{69,70}$ Our finding could support this hypothesis. If sexual dysfunction plays a role in the onset of depression, then it is reasonable to assume that it will be associated with the prognosis; however, this clearly requires confirmation in further studies. In patients on antidepressant therapy, low adherence related to treatmentemergent sexual dysfunction can also be hypothesized. ${ }^{69,71}$

The finding that current psychotherapy was associated with a lower likelihood of remission at 2 months was also unexpected. However, in the context of this analysis, being in psychotherapy should be considered as a patient characteristic indicating chronicity of depression or more complex disease (such as double depression or depression associated with personality disorders), rather than as a treatment intervention. This was supported by results of complementary analyses undertaken to explore this finding (Table S3). The observed association between country and likelihood of achieving remission is difficult to interpret, as it might stem from many different sources, including differences in clinical practice among participating countries, such as differences in the proportion of patients treated by psychiatrists and the type of antidepressant received.

Factors that appeared to be associated with an increased likelihood of relapse at month 6 in patients in remission at month 2 in this study were male sex, being married or living as a couple, residual depressive symptoms, and residual patient-reported cognitive symptoms. The role of sex as a factor associated with relapse in MDD remains uncertain, with previous studies yielding conflicting data. ${ }^{21,22,27,64}$ The relationship between marital status and depression is also complex; however, previous studies have shown low relationship satisfaction to be a risk factor for depression, which might explain the observed association between being married or living as a couple and relapse in this study. ${ }^{72-74}$

With regard to the association of higher PHQ-9 total score with increased likelihood of relapse, it is well documented that residual depressive symptoms after remission are associated with an increased risk of subsequent relapse in patients with MDD. ${ }^{29,66,75}$ It is not known how cognitive symptoms may influence clinical outcome in patients with MDD. Recent data suggest that cognitive impairment is a frequent residual symptom of MDD and a principal mediator of occupational impairment in patients in remission. ${ }^{76,77}$ Residual cognitive symptoms may also lead to persistent psychosocial impairment, or cognitive dysfunction may be associated with a cognitive affective bias. ${ }^{30}$ Cognitive symptoms might also impair adherence to treatment; however, data on this topic are lacking.

To our knowledge, this is the first demonstration that residual patient-reported cognitive symptoms may be associated with subsequent relapse in patients with MDD. In this analysis, each additional unit of PDQ-5 total score at month 2 was associated with a $12 \%$ increase in the odds of relapse at month 6 . The magnitude of effect for residual patientreported cognitive symptoms at month 2 was comparable to 
that of depressive symptoms at month 2 when expressed in terms of a change of $0.5 \mathrm{SD}$ to account for the difference in metrics between the PDQ-5 and PHQ-9 scales (range 0-20 and $0-27$, respectively). The extensive control for known factors associated with relapse in the final model and the supportive analyses demonstrate the consistency of these findings. These results need to be confirmed in further studies using objective tests of cognitive function. However, these findings suggest a role for assessment of cognitive function even with simple questions and in all settings, including primary care practices - to identify patients at higher risk of subsequent relapse after remission of MDD. While these results confirm that residual mood symptoms are a good target for detection of patients at risk of relapse of MDD, ${ }^{78,79}$ they also imply that therapeutic interventions that reduce residual cognitive dysfunction in patients with MDD who achieve remission could potentially lead to reduced risk of relapse. However, this requires confirmation in further studies before definitive recommendations can be made.

In this study, the remission rate at month 2 was $29.7 \%$; this is lower than typically reported in clinical trial settings, but is in line with the remission rate reported in more naturalistic studies, such as STAR*D. ${ }^{13}$ The relatively low remission rate highlights the fact that achieving remission is still a major unmet need for patients with MDD. The relapse rate at 6 months in this study was $19.7 \%$, which is lower than that reported in STAR*D. ${ }^{13}$ However, this may be at least in part due to the fact that there was only a 4-month interval between assessment of remission and relapse in this study; relapse rates are more typically assessed up to 6 months after achieving remission in clinical trials. An interesting next step will be to analyze relapse rates over longer follow-up.

Remission and relapse needed to be precisely defined in this study. Composite definitions relying on several different assessments were used to increase the likelihood of capturing remission and relapse, and to minimize the impact of missing data. PHQ-9 total score was chosen as the first criterion for these composite definitions. The PHQ-9 is a brief, selfadministered questionnaire specifically developed for evaluation of the severity of depressive symptoms, ${ }^{32}$ and is widely used in both research settings and clinical practice. PHQ-9 total score was assessed for all patients in the study, regardless of the setting (primary or specialized care). The second criterion used was MADRS total score. ${ }^{34}$ The MADRS is widely used to assess depression severity in randomized clinical trials of antidepressant therapy. ${ }^{80,81}$ This scale requires training to ensure reliable scoring, and was thus administered only by psychiatrists in this study; however, the majority of patients $(83.6 \%)$ were enrolled and followed up by general practitioners. The investigator-administered CGI-S was the final criterion for the composite definitions of remission and relapse; however, CGI-S score was only used if data were unavailable for both of the previous scales, as this assessment scale is not specific for depression. The composite definition of relapse included an additional criterion related to need for treatment modification for lack of efficacy at the 6-month visit. This criterion was added to capture the clinical evaluation of the physician, and is commonly used in definitions of relapse in relapse-prevention clinical trials.

Cutoff values for remission based on MADRS and CGI-S scores are well established. ${ }^{44-46,82}$ In contrast, several different cutoff values have been proposed for remission on the PHQ-9 scale. A PHQ-4 total score $<5$ has been used to define remission in some observational studies. ${ }^{56,83,84}$ However, this is based on the theoretical absence of depressive symptoms at this score, rather than an accepted definition of remission. ${ }^{32,85}$ Validation studies of the PHQ-9 scale established a score of 10 or higher as the cutoff for a diagnosis of depression. ${ }^{32}$ A recent meta-analysis found the PHQ-9 to have acceptable diagnostic properties for detecting MDD for cutoff scores between 8 and $11 .{ }^{86}$ However, the scale was found to be sensitive to clinical setting, which could affect the number of false positives and thus necessitate adapting the PHQ-9 cutoff used for remission in individual studies. Available data indicate an optimal threshold to define remission of between 7 and 12 on the PHQ-9 when compared with the CGI-S, and between 9 and 13 when compared with the MADRS, supporting the selected cutoff of 9 for the definition of remission used in this study. Indeed, this cutoff value has been used in other studies. ${ }^{87,88}$ With this definition, there is no gap between remission and relapse on the PHQ-9. To test if this induces a risk of misclassification of patients that could lead to biased estimates, additional supportive analyses using alternative definitions of remission and relapse were undertaken for the current study; using different thresholds yielded similar ORs for PDQ-5 and PHQ-9 effect at month 6.

A key strength of this study is that it was performed in a real-world setting with longitudinal follow-up of a large cohort of patients, the majority of whom were enrolled and followed up by primary care physicians. This suggests that the study findings are applicable to routine clinical practice, where patients with MDD are typically treated in primary care settings. In addition, the analysis was based on variables identified from a literature review as being clinically relevant factors. The literature review yielded concepts and notions that we tried to capture using available PERFORM data. For example, substance abuse is captured both by the tobacco-use covariate and the concomitant mental disorder 
covariate. Some variables were added to the list of covariates, as they were considered important for the outcome of the disease (eg, disease management and important life events). Country, age, sex, and PHQ-9 total score (at baseline for the remission analysis and at month 2 for the relapse analysis) were forced into the model as adjustment variables, because they were identified as potential confounders. The effects of treatment in the study population were addressed via covariates reflecting the type of treatment (psychotherapy) and meaningful treatment patterns (treatment switch, treatment stop, and line of treatment). The drug received was not taken into account, as the study design and data-collection method did not allow for assessment of treatment effect.

A potential limitation is the fact that the PHQ-9 is completed by patients, while the MADRS and CGI-S are completed by physicians, which may have introduced differences in estimation of rates of remission and relapse between the different measures. For analysis of factors associated with relapse in patients who were in remission at month 2 , fewer variables were selected from the univariate analysis; this is most likely due to the relatively limited sample size. Nevertheless, results of the supportive analyses using the forward-selection process were consistent with the ORs obtained using the backward-selection process, confirming the robustness of the statistical model. Regarding relapse, it is important to note that this study was observational and differs in design from relapse-prevention trials. In particular, there was only a 4-month interval between assessment of remission and relapse in this study. In addition, cognitive dysfunction was assessed using a patient-reported questionnaire, and little has been published regarding the extent to which PDQ-5 score reflects or is correlated with objective measures; however, this is relevant from a routine-practice perspective, as objective neuropsychological tests are not used in primary care settings.

\section{Conclusion}

In summary, results of this large observational study suggest that certain sociodemographic and clinical characteristics may be associated with an increased likelihood of failure to achieve remission in patients with MDD or with subsequent relapse in patients who do achieve remission. In particular, cognitive dysfunction appears to be an easily measurable patient characteristic that may be associated with an increased likelihood of relapse at 6 months in patients who have achieved remission. This finding suggests that therapeutic interventions that reduce residual cognitive dysfunction in patients who achieve remission could lead to a reduced risk of relapse of MDD. Further studies are needed to confirm this and to provide evidence on the magnitude of the effect and its importance for clinical practice.

\section{Acknowledgments}

This study was funded by Lundbeck SAS. The authors would like to express their gratitude to all the physicians and patients who kindly provided data for the study. Writing and editorial assistance was provided by Jennifer Coward of Anthemis Consulting Ltd, funded by Lundbeck SAS. The authors also thank MAPI Registrat for the logistical management of the study.

\section{Disclosure}

JMH has received honoraria for being an advisor or providing education talks for Lundbeck, Otsuka, Roche, and Eli Lilly and Company. BJ has received honoraria for being an advisor to Lundbeck. MK has received consultancy funding from Lundbeck and Takeda, and has received research funding from Lundbeck. DS and BR are full-time employees of Lundbeck SAS. MT is a full-time employee of Lundbeck LLC. At the time the study was conducted, BB was an employee of Inferential, which received funding from Lundbeck SAS, and his current affiliation is Innovus Consulting Ltd, London, UK. IF and HL are full-time employees of H Lundbeck AS. The authors report no other conflicts of interest in this work.

\section{References}

1. Kessler RC, Birnbaum HG, Shahly V, et al. Age differences in the prevalence and co-morbidity of DSM-IV major depressive episodes: results from the WHO World Mental Health Survey Initiative. Depress Anxiety. 2010;27(4):351-364.

2. Global Burden of Disease Study 2013 Collaborators. Global, regional, and national incidence, prevalence, and years lived with disability for 301 acute and chronic diseases and injuries in 188 countries, 1990-2013: a systematic analysis for the Global Burden of Disease Study 2013. Lancet. 2015;386(9995):743-800.

3. Kessler RC, Berglund P, Demler O, et al. The epidemiology of major depressive disorder: results from the National Comorbidity Survey Replication (NCS-R). JAMA. 2003;289(23):3095-3105.

4. McKnight PE, Kashdan TB. The importance of functional impairment to mental health outcomes: a case for reassessing our goals in depression treatment research. Clin Psychol Rev. 2009;29(3):243-259.

5. Kennedy SH, Eisfeld BS, Cooke RG. Quality of life: an important dimension in assessing the treatment of depression? J Psychiatry Neurosci. 2001; 26 Suppl:S23-S28.

6. Katon W. The impact of depression on workplace functioning and disability costs. Am J Manag Care. 2009;15(11 Suppl):S322-S327.

7. Kennedy SH, Andersen HF, Thase ME. Escitalopram in the treatment of major depressive disorder: a meta-analysis. Curr Med Res Opin. 2009;25(1):161-175.

8. Thase ME, Entsuah AR, Rudolph RL. Remission rates during treatment with venlafaxine or selective serotonin reuptake inhibitors. $\mathrm{Br} J$ Psychiatry. 2001;178:234-241.

9. Thase ME, Pritchett YL, Ossanna MJ, Swindle RW, Xu J, Detke MJ. Efficacy of duloxetine and selective serotonin reuptake inhibitors: comparisons as assessed by remission rates in patients with major depressive disorder. J Clin Psychopharmacol. 2007;27(6):672-676. 
10. Thase ME, Kornstein SG, Germain JM, Jiang Q, Guico-Pabia C, Ninan PT. An integrated analysis of the efficacy of desvenlafaxine compared with placebo in patients with major depressive disorder. CNS Spectr. 2009;14(3):144-154.

11. Thase ME, Nierenberg AA, Vrijland P, van Oers HJ, Schutte AJ, Simmons JH. Remission with mirtazapine and selective serotonin reuptake inhibitors: a meta-analysis of individual patient data from 15 controlled trials of acute phase treatment of major depression. Int Clin Psychopharmacol. 2010;25(4):189-198.

12. Thase ME, Mahableshwarkar AR, Dragheim M, Loft H, Vieta E. A meta-analysis of randomized, placebo-controlled trials of vortioxetine for the treatment of major depressive disorder in adults. Eur Neuropsychopharmacol. 2016;26(6):979-993.

13. Rush AJ, Trivedi MH, Wisniewski SR, et al. Acute and longer-term outcomes in depressed outpatients requiring one or several treatment steps: a STAR*D report. Am J Psychiatry. 2006;163(11):1905-1917.

14. Warden D, Rush AJ, Trivedi MH, Fava M, Wisniewski SR. The STAR*D project results: a comprehensive review of findings. Curr Psychiatry Rep. 2007;9(6):449-459.

15. Kim JM, Kim SW, Stewart R, et al. Predictors of 12-week remission in a nationwide cohort of people with depressive disorders: the CRESCEND study. Hum Psychopharmacol. 2011;26(1):41-50.

16. Mauskopf JA, Simon GE, Kalsekar A, Nimsch C, Dunayevich E, Cameron A. Nonresponse, partial response, and failure to achieve remission: humanistic and cost burden in major depressive disorder. Depress Anxiety. 2009;26(1):83-97.

17. Byford S, Barrett B, Despiégel N, Wade A. Impact of treatment success on health service use and cost in depression: longitudinal database analysis. Pharmacoeconomics. 2011;29(2):157-170.

18. Kubitz N, Mehra M, Potluri RC, Garg N, Cossrow N. Characterization of treatment resistant depression episodes in a cohort of patients from a US commercial claims database. PLoS One. 2013;8(10):e76882.

19. Dennehy EB, Robinson RL, Stephenson JJ, et al. Impact of nonremission of depression on costs and resource utilization: from the comorbidities and symptoms of depression (CODE) study. Curr Med Res Opin. 2015;31(6):1165-1177.

20. Judd LL, Schettler PJ, Rush AJ. A brief clinical tool to estimate individual patients' risk of depressive relapse following remission: proof of concept. Am J Psychiatry. 2016;173(11):1140-1146.

21. Trivedi MH, Rush AJ, Wisniewski SR, et al. Evaluation of outcomes with citalopram for depression using measurement-based care in STAR*D: implications for clinical practice. Am J Psychiatry. 2006; 163(1):28-40.

22. Cheung A. Anxiety as a predictor of treatment outcome in children and adolescents with depression. J Child Adolesc Psychopharmacol. 2010;20(3):211-216.

23. Barkow K, Maier W, Ustün TB, Gänsicke M, Wittchen HU, Heun R. Risk factors for depression at 12-month follow-up in adult primary health care patients with major depression: an international prospective study. J Affect Disord. 2003;76(1-3):157-169.

24. WeinbergerMI, Sirey JA, Bruce ML, Heo M, PapademetriouE, Meyers BS. Predictors of major depression six months after admission for outpatient treatment. Psychiatr Serv. 2008;59(10):1211-1215.

25. O'Leary D, Costello F, Gormley N, Webb M. Remission onset and relapse in depression: an 18-month prospective study of course for 100 first admission patients. J Affect Disord. 2000;57(1-3):159-171.

26. Katon W, Unützer J, Russo J. Major depression: the importance of clinical characteristics and treatment response to prognosis. Depress Anxiety. 2010;27(1):19-26.

27. McGrath PJ, Stewart JW, Quitkin FM, et al. Predictors of relapse in a prospective study of fluoxetine treatment of major depression. Am J Psychiatry. 2006;163(9):1542-1548.

28. ten Doesschate MC, Bockting CL, Koeter MW, Schene AH. Prediction of recurrence in recurrent depression: a 5.5-year prospective study. J Clin Psychiatry. 2010;71(8):984-991.

29. Nierenberg AA, Husain MM, Trivedi MH, et al. Residual symptoms after remission of major depressive disorder with citalopram and risk of relapse: a STAR*D report. Psychol Med. 2010;40(1):41-50.
30. Lam RW, Kennedy SH, Mclntyre RS, Khullar A. Cognitive dysfunction in major depressive disorder: effects on psychosocial functioning and implications for treatment. Can J Psychiatry. 2014;59(12): 649-654.

31. Gonda X, Pompili M, Serafini G, Carvalho AF, Rihmer Z, Dome P. The role of cognitive dysfunction in the symptoms and remission from depression. Ann Gen Psychiatry. 2015;14:27.

32. Kroenke K, Spitzer RL, Williams JB. The PHQ-9: validity of a brief depression severity measure. J Gen Intern Med. 2001;16(9):606-613.

33. Guy W. CGI: Clinical Global Impressions. In: ECDEU Assessment Manual for Psychopharmacology. Rockville (MD): National Institute of Mental Health; 1976:217-222.

34. Montgomery SA, Asberg M. A new depression scale designed to be sensitive to change. Br J Psychiatry. 1979;134:382-389.

35. Sullivan JJ, Edgley K, Dehoux E. A survey of multiple sclerosis - part 1: perceived cognitive problems and compensatory strategy use. Can J Rehabil. 1990;4(2):99-105.

36. National Multiple Sclerosis Society. Multiple Sclerosis Quality of Life Inventory: A User's Manual. New York: NMSS; 1997.

37. Hamilton $\mathrm{M}$. The assessment of anxiety states by rating. $\mathrm{Br} \mathrm{J} \mathrm{Med}$ Psychol. 1959;32(1):50-55.

38. Sheehan DV, Harnett-Sheehan K, Raj BA. The measurement of disability. Int Clin Psychopharmacol. 1996;11(Suppl 3):89-95.

39. Reilly MC, Zbrozek AS, Dukes EM. The validity and reproducibility of a work productivity and activity impairment instrument. Pharmacoeconomics. 1993;4(5):353-365.

40. Ware J Jr, Kosinski M, Keller SD. A 12-item short-form health survey: construction of scales and preliminary tests of reliability and validity. Med Care. 1996;34(3):220-233.

41. EuroQol Group. EuroQol: a new facility for the measurement of healthrelated quality of life. Health Policy. 1990;16(3):199-208.

42. McGahuey CA, Gelenberg AJ, Laukes CA, et al. The Arizona Sexual Experience Scale (ASEX): reliability and validity. J Sex Marital Ther. 2000;26(1):25-40.

43. Morisky DE, Green LW, Levine DM. Concurrent and predictive validity of a self-reported measure of medication adherence. Med Care. 1986;24(1):67-74

44. Hawley CJ, Gale TM, Sivakumaran T. Defining remission by cut off score on the MADRS: selecting the optimal value. $J$ Affect Disord. 2002;72(2):177-184.

45. Zimmerman M, Posternak MA, Chelminski I. Derivation of a definition of remission on the Montgomery-Asberg depression rating scale corresponding to the definition of remission on the Hamilton rating scale for depression. J Psychiatr Res. 2004;38(6):577-582.

46. Dunlop BW, Li T, Kornstein SG, et al. Concordance between clinician and patient ratings as predictors of response, remission, and recurrence in major depressive disorder. J Psychiatr Res. 2011;45(1):96-103.

47. Frank E, Prien RF, Jarrett RB, et al. Conceptualization and rationale for consensus definitions of terms in major depressive disorder: remission, recovery, relapse, and recurrence. Arch Gen Psychiatry. 1991;48(9): $851-855$.

48. Geddes JR, Carney SM, Davies C, et al. Relapse prevention with antidepressant drug treatment in depressive disorders: a systematic review. Lancet. 2003;361(9358):653-661.

49. Spijker J, Bijl RV, de Graaf R, Nolen WA. Determinants of poor 1-year outcome of DSM-III-R major depression in the general population: results of the Netherlands Mental Health Survey and Incidence Study (NEMESIS). Acta Psychiatr Scand. 2001;103(2):122-130.

50. Kloiber S, Ising M, Reppermund S, et al. Overweight and obesity affect treatment response in major depression. Biol Psychiatry. 2007;62(4):321-326.

51. Fava M, Wiltse C, Walker D, Brecht S, Chen A, Perahia D. Predictors of relapse in a study of duloxetine treatment in patients with major depressive disorder. J Affect Disord. 2009;113(3):263-271.

52. Rucci P, Frank E, Calugi S, et al. Incidence and predictors of relapse during continuation treatment of major depression with SSRI, interpersonal psychotherapy, or their combination. Depress Anxiety. 2011;28(11):955-962. 
53. Nordenskjöld A, von Knorring L, Engström I. Predictors of time to relapse/recurrence after electroconvulsive therapy in patients with major depressive disorder: a population-based cohort study. Depress Res Treat. 2011;2011:470985.

54. Trinh NH, Shyu I, McGrath PJ, et al. Examining the role of race and ethnicity in relapse rates of major depressive disorder. Compr Psychiatry. 2011;52(2):151-155.

55. McGrath PJ, Stewart JW, Petkova E, et al. Predictors of relapse during fluoxetine continuation or maintenance treatment of major depression. J Clin Psychiatry. 2000;61(7):518-524.

56. Angstman KB, Shippee ND, Maclaughlin KL, et al. Patient self-assessment factors predictive of persistent depressive symptoms 6 months after enrollment in collaborative care management. Depress Anxiety. 2013; 30(2):143-148.

57. Wang JL, Patten SB, Currie S, Sareen J, Schmitz N. Predictors of 1-year outcomes of major depressive disorder among individuals with a lifetime diagnosis: a population-based study. Psychol Med. 2012; 42(2):327-334.

58. Papakostas GI, Larsen K. Testing anxious depression as a predictor and moderator of symptom improvement in major depressive disorder during treatment with escitalopram. Eur Arch Psychiatry Clin Neurosci. 2011;261(3):147-156

59. Kessing LV. Subtypes of depressive episodes according to ICD-10: prediction of risk of relapse and suicide. Psychopathology. 2003;36(6): 285-291.

60. Jang S, Jung S, Pae C, Kimberly BP, Nelson JC, Patkar AA. Predictors of relapse in patients with major depressive disorder in a 52-week, fixed dose, double blind, randomized trial of selegiline transdermal system (STS). J Affect Disord. 2013;151(3):854-859.

61. Yang H, Chuzi S, Sinicropi-Yao L, et al. Type of residual symptom and risk of relapse during the continuation/maintenance phase treatment of major depressive disorder with the selective serotonin reuptake inhibitor fluoxetine. Eur Arch Psychiatry Clin Neurosci. 2010;260(2):145-150.

62. Sheets ES, Duncan LE, Bjornsson AS, Craighead LW, Craighead WE. Personality pathology factors predict recurrent major depressive disorder in emerging adults. J Clin Psychol. 2014;70(6):536-545.

63. Riedel M, Möller HJ, Obermeier M, et al. Clinical predictors of response and remission in inpatients with depressive syndromes. $J$ Affect Disord. 2011;133(1-2):137-149.

64. Gopinath S, Katon WJ, Russo JE, Ludman EJ. Clinical factors associated with relapse in primary care patients with chronic or recurrent depression. J Affect Disord. 2007;101(1-3):57-63.

65. Zimmerman M, McGlinchey JB, Posternak MA, Friedman M, Boerescu D, Attiullah N. Remission in depressed outpatients: more than just symptom resolution? J Psychiatr Res. 2008;42(10):797-801.

66. Paykel ES, Ramana R, Cooper Z, Hayhurst H, Kerr J, Barocka A. Residual symptoms after partial remission: an important outcome in depression. Psychol Med. 1995;25(6):1171-1180.

67. Ishak WW, Greenberg JM, Cohen RM. Predicting relapse in major depressive disorder using patient-reported outcomes of depressive symptom severity, functioning, and quality of life in the Individual Burden of Illness Index for Depression (IBI-D). J Affect Disord. 2013;151(1):59-65.

68. Novick D, Hong J, Montgomery W, Dueñas H, Gado M, Haro JM. Predictors of remission in the treatment of major depressive disorder: real-world evidence from a 6-month prospective observational study. Neuropsychiatr Dis Treat. 2015;11:197-205.

69. Seidman S. Ejaculatory dysfunction and depression: pharmacological and psychobiological interactions. Int J Impot Res. 2006;18 (Suppl 1): S33-S38.

70. Clayton AH, El Haddad S, Iluonakhamhe JP, Ponce Martinez C, Schuck AE. Sexual dysfunction associated with major depressive disorder and antidepressant treatment. Expert Opin Drug Saf. 2014;13(10):1361-1374.
71. Ashton AK, Jamerson BD, Weinstein WL, Wagoner C. Antidepressantrelated adverse effects impacting treatment compliance: results of a patient survey. Curr Ther Res Clin Exp. 2005;66(2):96-106.

72. Whisman MA. Depression and marital distress: findings from clinical and community studies. In: Beach SR, editor. Marital and Family Processes in Depression. Washington: American Psychological Association; 2001:3-24.

73. Whisman MA. Marital distress and DSM-IV psychiatric disorders in a population-based national survey. $J$ Abnorm Psychol. 2007;116(3):638-643.

74. Whisman MA, Uebelacker LA. Prospective associations between marital discord and depressive symptoms in middle-aged and older adults. Psychol Aging. 2009;24(1):184-189.

75. Judd LL, Paulus MJ, Schettler PJ, et al. Does incomplete recovery from first lifetime major depressive episode herald a chronic course of illness? Am J Psychiatry. 2000;157(9):1501-1504.

76. Bortolato B, Carvalho AF, McIntyre RS. Cognitive dysfunction in major depressive disorder: a state-of-the-art clinical review. CNS Neurol Disord Drug Targets. 2014;13(10):1804-1818.

77. Woo YS, Rosenblat JD, Kakar R, Bahk WM, McIntyre RS. Cognitive deficits as a mediator of poor occupational function in remitted major depressive disorder patients. Clin Psychopharmacol Neurosci. 2016;14(1):1-16.

78. Kurian BT, Greer TL, Trivedi MH. Strategies to enhance the therapeutic efficacy of antidepressants: targeting residual symptoms. Expert Rev Neurother. 2009;9(7):975-984.

79. Zajecka J, Kornstein SG, Blier P. Residual symptoms in major depressive disorder: prevalence, effects, and management. J Clin Psychiatry. 2013;74(4):407-414.

80. Khan A, Khan SR, Shankles EB, Polissar NL. Relative sensitivity of the Montgomery-Ásberg Depression Rating Scale, the Hamilton Depression Rating Scale and the Clinical Global Impressions Rating Scale in antidepressant clinical trials. Int Clin Psychopharmacol. 2002;17(6):281-285.

81. Jiang Q, Ahmed S. An analysis of correlations among four outcome scales employed in clinical trials of patients with major depressive disorder. Ann Gen Psychiatry. 2009;8:4.

82. Trivedi MH, Corey-Lisle PK, Guo Z, Lennox RD, Pikalov A, Kim E. Remission, response without remission, and nonresponse in major depressive disorder: impact on functioning. Int Clin Psychopharmacol. 2009;24(3):133-138.

83. Katzelnick DJ, Duffy FF, Chung H, Regier DA, Rae DS, Trivedi MH. Depression outcomes in psychiatric clinical practice: using a self-rated measure of depression severity. Psychiatr Serv. 2011;62(8):929-935.

84. Garrison GM, Angstman KB, O’Connor SS, Williams MD, Lineberry TW. Time to remission for depression with collaborative care management (CCM) in primary care. J Am Board Fam Med. 2016;29(1):10-17.

85. McMillan D, Gilbody S, Richards D. Defining successful treatment outcome in depression using the PHQ-9: a comparison of methods. $J$ Affect Disord. 2010;127(1-3):122-129.

86. Manea L, Gilbody S, McMillan D. Optimal cut-off score for diagnosing depression with the Patient Health Questionnaire (PHQ-9): a metaanalysis. CMAJ. 2012;184(3):E191-E196.

87. Ell K, Katon W, Lee PJ, et al. Depressive symptom deterioration among predominantly Hispanic diabetes patients in safety net care. Psychosomatics. 2012;53(4):347-355.

88. Horne D, Kehler S, Kaoukis G, et al. Depression before and after cardiac surgery: do all patients respond the same? J Thorac Cardiovasc Surg. 2013;145(5):1400-1406. 


\section{Supplementary materials}

Table SI Details of backward-selection process for analysis of factors associated with remission at month 2

\begin{tabular}{|c|c|c|c|c|c|c|}
\hline Step & Factors in model & Factor removed & OR $(95 \% \mathrm{Cl})$ & $P$-value & AIC & BIC \\
\hline 0 & 23 & - & - & - & 684.158 & 815.460 \\
\hline I & 22 & At least one other concomitant mental disorder & $1.00(0.52-1.92)$ & 0.9910 & 682.158 & 809.083 \\
\hline 2 & 21 & Chronic pain or fibromyalgia & $1.03(0.57-1.88)$ & 0.9185 & 680.169 & 802.717 \\
\hline 3 & 20 & SF-I 2 - mental health (MCS) & $1.00(0.97-1.04)^{\mathrm{a}}$ & 0.8809 & 678.191 & 796.363 \\
\hline 4 & 19 & Tobacco use & $1.09(0.71-1.68)$ & 0.6871 & 676.353 & 790.148 \\
\hline 5 & 18 & Sick leave within the 12 months before baseline & $0.87(0.55-1.36)$ & 0.5348 & 674.740 & 784.158 \\
\hline 6 & 17 & At least one chronic medical condition & $0.82(0.50-1.34)$ & 0.4278 & 673.373 & 778.415 \\
\hline 7 & 16 & Switch of antidepressant & $1.24(0.73-2.10)$ & 0.4253 & 672.004 & 772.669 \\
\hline 8 & 15 & Hospitalization for depression during the 12 weeks before baseline & $0.58(0.15-2.28)$ & 0.4336 & 670.671 & 766.959 \\
\hline 9 & 14 & SF-12 - physical health (PCS) & $1.01(0.99-1.03)^{\mathrm{a}}$ & 0.2907 & 669.792 & 761.703 \\
\hline 10 & 13 & WPAI - percentage activity impairment due to problem & $1.01(1.00-1.02)^{\mathrm{a}}$ & 0.1753 & 669.654 & 757.188 \\
\hline 11 & 12 & PDQ-5 total score & $0.97(0.91-1.02)^{\mathrm{a}}$ & 0.2426 & 669.020 & 752.178 \\
\hline 12 & 11 & Living area & $1.37(0.89-2.12)^{\mathrm{b}}$ & 0.1502 & 669.082 & 747.863 \\
\hline 13 & 10 & CGI-S & $0.85(0.70-1.04)^{\mathrm{a}}$ & 0.1127 & 669.574 & 743.978 \\
\hline 14 & 9 & Educational level (4 categories) & $1.67(0.95-2.94)^{c}$ & 0.1277 & 669.435 & 730.709 \\
\hline 14 & 9 & Educational level (4 categories) & $1.82(0.92-3.59)^{\mathrm{d}}$ & - & - & - \\
\hline 14 & 9 & Educational level (4 categories) & $1.95(1.09-3.48)^{\mathrm{e}}$ & - & - & - \\
\hline 15 & 8 & Suicide attempt - before baseline & $0.44(0.18-1.04)$ & 0.0624 & 671.406 & 728.304 \\
\hline
\end{tabular}

Notes: ${ }^{a}$ Continuous factor; ${ }^{b}$ rural vs urban; chigh school vs no degree or diploma/elementary school; ${ }^{\circledR}$ non-university degree vs no degree or diploma/elementary school; euniversity degree vs no degree or diploma/elementary school.

Abbreviations: AIC, Akaike Information Criterion; BIC, Bayesian Information Criterion; CGI-S, Clinical Global Impressions-severity of illness; MCS, mental component summary; PCS, physical component summary; PDQ-5, 5-item Perceived Deficit Questionnaire; SF-12, 12-item Short-Form Health Survey; WPAI, Work Productivity and Activity Impairment.

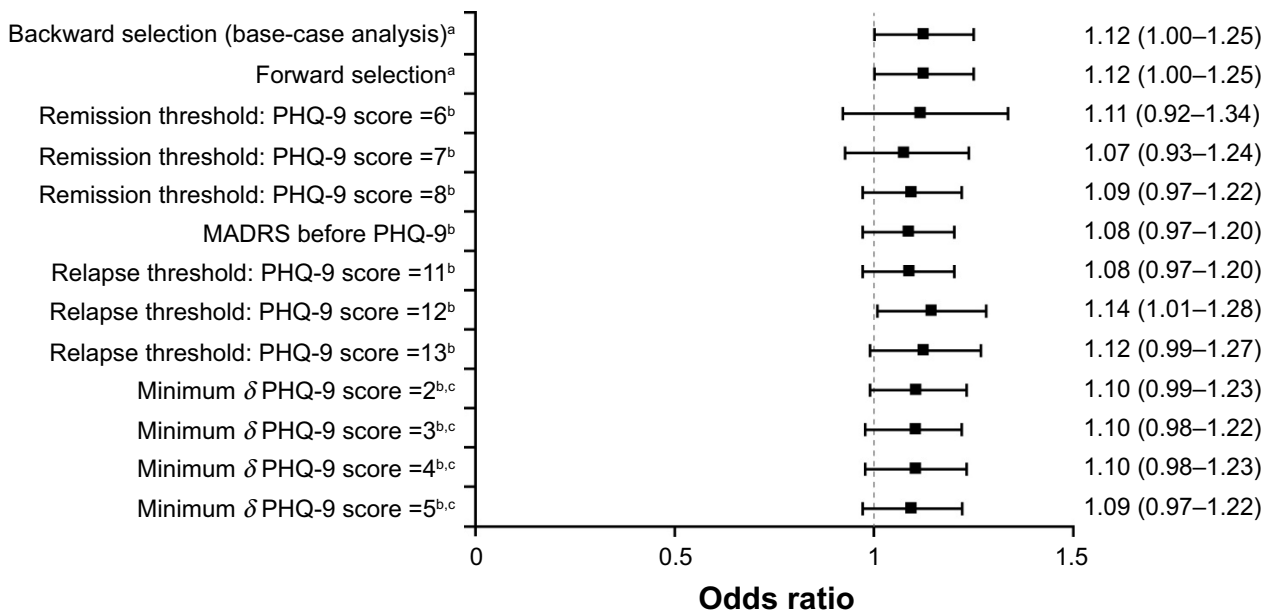

Figure SI Summary of supportive analyses of PDQ-5 effect on relapse at month 6.

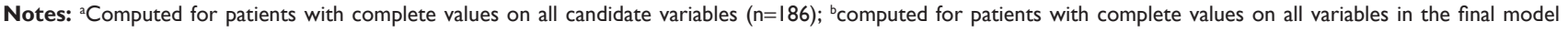
( $n=193$ ); cadditional criterion for relapse definition: minimum change in PHQ-9 total score between month 2 and month 6 . Values expressed as OR (95\% Cl).

Abbreviations: MADRS, Montgomery-Åsberg Depression Rating Scale; PHQ-9, 9-item Public Health Questionnaire. 


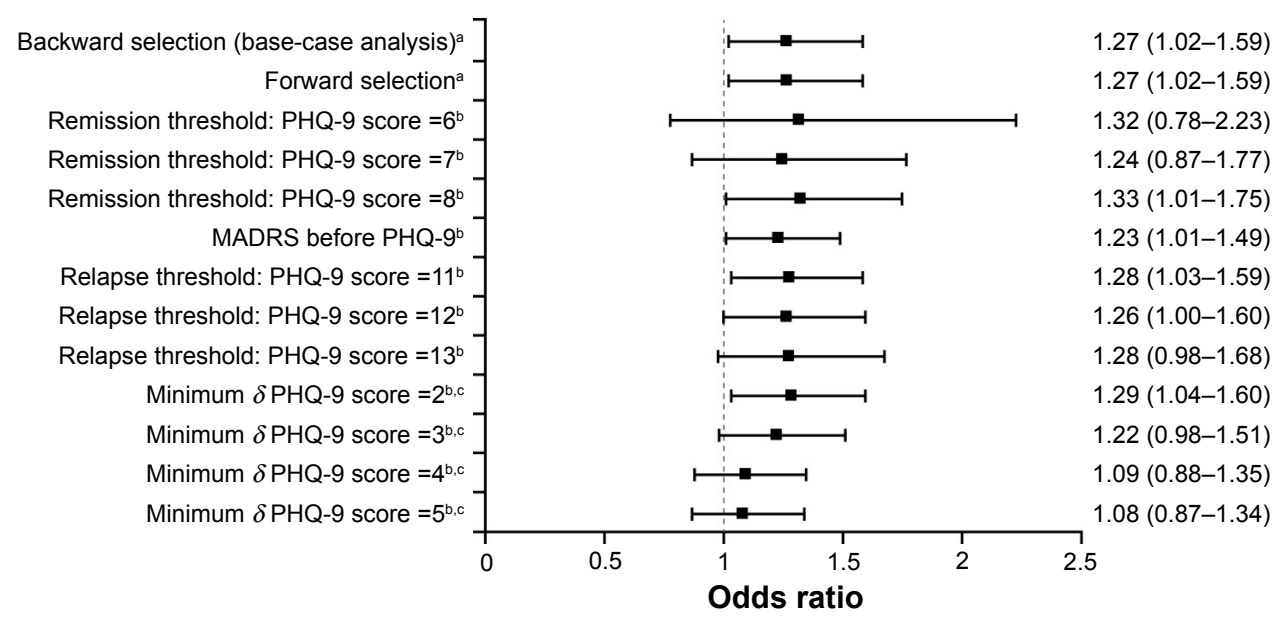

Figure S2 Summary of supportive analyses of PHQ-9 effect on relapse at month 6.

Notes: a Computed for patients with complete values on all candidate variables $(n=186)$; ${ }^{b}$ computed for patients with complete values on all variables in the final model ( $n=193$ ); ' additional criterion for relapse definition: minimum change in PHQ-9 total score between month 2 and month 6 . Values expressed as OR (95\% Cl).

Abbreviations: MADRS, Montgomery-Åsberg Depression Rating Scale; PHQ-9, 9-item Public Health Questionnaire.

Table S2 Details of backward-selection process for analysis of factors associated with relapse at month 6 for patients in remission at month 2

\begin{tabular}{|c|c|c|c|c|c|c|}
\hline Step & Factors in model & Factor removed & OR $(95 \% \mathrm{Cl})$ & $P$-value & AIC & BIC \\
\hline 0 & 12 & - & - & - & 178.837 & 230.449 \\
\hline 1 & 11 & WPAI - percentage activity impairment due to problem (M2) & $1.00(0.97-1.03)$ & 0.9937 & 176.837 & 225.223 \\
\hline 2 & 10 & $\begin{array}{l}\text { Switch of antidepressant at baseline, between baseline and } M 2 \text {, } \\
\text { or at M2 (up to M2) }\end{array}$ & $1.48(0.56-3.92)$ & 0.4349 & 175.437 & 220.598 \\
\hline 3 & 9 & SF-12 - mental health (MCS - M2) & $0.97(0.92-1.03)$ & 0.3213 & 174.428 & 216.362 \\
\hline 4 & 8 & CGI-S (M2) & $1.40(0.92-2.13)$ & 0.1087 & 175.093 & 213.802 \\
\hline 5 & 7 & $\begin{array}{l}\text { Suicide attempt before baseline or between baseline and } M 2 \\
\text { (up to } M 2 \text { ) }\end{array}$ & $4.6 \mathrm{I}(0.83-25.5 \mathrm{I})$ & 0.0844 & |75.98| & 211.464 \\
\hline 6 & 6 & SF-12 - physical health (PCS - M2) & $0.96(0.92-1.00)$ & 0.0667 & 177.333 & 209.591 \\
\hline
\end{tabular}

Abbreviations: AIC, Akaike Information Criterion; BIC, Bayesian Information Criterion; CGI-S, Clinical Global Impressions-severity of illness; M2, month 2; MCS, mental component summary; PCS, physical component summary; PDQ-5, 5-item Perceived Deficit Questionnaire; SF-I2, I2-item Short-Form Health Survey; WPAI, Work Productivity and Activity Impairment. 
Table S3 Complementary analysis comparing factors identified as potential indicators of severity and chronicity of depression according to psychotherapy at baseline

\begin{tabular}{|c|c|c|c|}
\hline Factor & Psychotherapy $(n=158)$ & No psychotherapy $(n=954)$ & $P$-value ${ }^{a}$ \\
\hline \multicolumn{4}{|c|}{ Is the current episode the patient's first depressive episode? } \\
\hline Yes & $60(38.2 \%)$ & $425(44.6 \%)$ & \multirow[t]{2}{*}{$0.135\left(\chi^{2}\right)$} \\
\hline No & $97(61.8 \%)$ & $528(55.4 \%)$ & \\
\hline \multicolumn{4}{|l|}{ If no: } \\
\hline \multicolumn{4}{|c|}{ Previous psychotherapy } \\
\hline Yes & $67(69.1 \%)$ & $159(30.2 \%)$ & $<0.001\left(\chi^{2}\right)$ \\
\hline \multicolumn{4}{|c|}{ Did your patient achieve remission after this episode? } \\
\hline Yes & 77 (79.4\%) & $442(83.7 \%)$ & $0.296\left(\chi^{2}\right)$ \\
\hline \multicolumn{4}{|c|}{ Has the patient been hospitalized for depression? } \\
\hline Yes & $13(13.4 \%)$ & $42(8.0 \%)$ & $0.082\left(\chi^{2}\right)$ \\
\hline \multicolumn{4}{|c|}{ Has the patient ever attempted suicide? } \\
\hline Yes & $15(15.5 \%)$ & $70(13.3 \%)$ & $0.560\left(\chi^{2}\right)$ \\
\hline \multicolumn{4}{|c|}{ Time since beginning of this depressive episode ( 3 categories) } \\
\hline$<4$ weeks & $33(20.9 \%)$ & $284(29.8 \%)$ & \multirow[t]{3}{*}{$0.058\left(\chi^{2}\right)$} \\
\hline 4-8 weeks & $38(24.1 \%)$ & $186(19.5 \%)$ & \\
\hline$>8$ weeks & $87(55.1 \%)$ & $482(50.6 \%)$ & \\
\hline \multicolumn{4}{|c|}{ Patient considered "difficult to treat" or "treatment-resistant"? } \\
\hline Yes & $33(20.9 \%)$ & $112(11.8 \%)$ & $0.002\left(\chi^{2}\right)$ \\
\hline \multicolumn{4}{|c|}{ Is the current depressive episode already being treated with } \\
\hline \multicolumn{4}{|c|}{ an antidepressant (prior to this visit)? } \\
\hline Yes & $4 \mathrm{I}(25.9 \%)$ & $200(21.0 \%)$ & $0.163\left(\chi^{2}\right)$ \\
\hline \multicolumn{4}{|c|}{ At least one chronic medical condition } \\
\hline Yes & $4 \mathrm{I}(25.9 \%)$ & $254(26.6 \%)$ & $0.859\left(\chi^{2}\right)$ \\
\hline \multicolumn{4}{|c|}{ At least one important life event } \\
\hline Yes & $74(54.8 \%)$ & $386(48.7 \%)$ & $0.192\left(\chi^{2}\right)$ \\
\hline \multicolumn{4}{|c|}{ PHQ-9 total score } \\
\hline Mean \pm SD & $18.1 \pm 5.2$ & $17.5 \pm 5.4$ & 0.311 \\
\hline \multicolumn{4}{|l|}{ CGI-S } \\
\hline Mean \pm SD & $4.4 \pm 1.1$ & $4.1 \pm 1.0$ & 0.003 \\
\hline
\end{tabular}

Note: ${ }^{\text {a }} \chi^{2}$ test or Fisher's exact test for categorical variables, Student's $t$-test for continuous variables.

Abbreviations: CGI-S, Clinical Global Impressions-severity of illness; PHQ-9, 9-item Patient Health Questionnaire.

\section{Publish your work in this journal}

Neuropsychiatric Disease and Treatment is an international, peerreviewed journal of clinical therapeutics and pharmacology focusing on concise rapid reporting of clinical or pre-clinical studies on a range of neuropsychiatric and neurological disorders. This journal is indexed on PubMed Central, the 'PsycINFO' database and CAS, and is the official journal of The International Neuropsychiatric Association (INA). The manuscript management system is completely online and includes a very quick and fair peer-review system, which is all easy to use. Visit http://www.dovepress.com/testimonials.php to read real quotes from published authors.

Submit your manuscript here: http://www.dovepress.com/neuropsychiatric-disease-and-treatment-journal 